

\section{Abstract}

In this paper we propose a culture-based health promotion/disease prevention intervention model. This model, which is family-based, incorporates a life course perspective, which involves the identification of individual developmental milestones, and incorporates aspects of culture that have been widely used across cultures to influence behaviour and mark important developmental transitions. Central among those cultural traits is the ritual, or rite of passage, which, for millennia, has been used to teach the skills associated with developmental task mastery and move individuals, and their families, through life stages so that they reach certain developmental milestones. Family rituals, such as eating dinner together, can serve as powerful leverage points to support health behaviour change, and serve as unique intervention delivery strategies that not only influence behaviour, but further strengthen families.

Keywords: Latinos; interventions; nutrition; community health. 


\title{
Using Rituals for Intervention Refinement
}

\author{
C. Keller, K. Coe \& G. Shaibi
}

\section{Introduction}

The aim of this paper is to describe a new model that incorporates a life course perspective and focuses on the role rituals can play in shaping an individual's health and health behaviours throughout his/her lifespan. Based on the assumption that a life course perspective and knowledge of the key cultural practice are essential for promoting behaviour change that persists, this model places an emphasis on developmental transitions and milestones by drawing on key cultural traits - rituals -- that have been used through time and across societies to influence behaviour during those developmental stages.

A common theoretical challenge in developing any intervention is coming up with a design that facilitates its utilization in different cultural contexts. While we assume, as do others, that cultural tailoring is important, it also should be recognized that not all cultural practices are healthful. For this reason, we turned our focus to the incorporation of traditions that are found across cultures and that endured, passed for thousands of years from one generation of kin to the next. These traditions presumably persisted because they were built upon biological underpinnings and, on average, had a positive effect; an understanding of such traditions can yield insights and approaches that are "of practical value in the present" (Zartman, 2000: 9). What is distinct about our approach is 1) strong focus on the family and the unique developmental trajectory of each of its members and 2) the belief that rituals can contribute not only to family functioning but can play a key role in promoting enduring healthy behaviour change.

\section{The theoretical foundation of the proposed model}

Significant research and thought reports provide strong support that there is a serious need to promote health and prevent disease in community settings among all age groups and within developmental milestones (Israel, 1998). Although there is little evidence that one theoretical behavioural approach is most efficacious, there is significant agreement that interventions work best if they include a multilevel approach that is tailored to individuals with appreciation for local settings (Israel, 1998; Castro, 2004; Green, 2001; Green, 2006; Green, 2009). We have developed this model based on the assumption that health behaviours are influenced by the contextual realities of cultural, ethnic and family groups.

An implication underlying the assumption that developmental transitions are rooted in norms and expectations related to age, developmental stage and social transitions (Giele \& Elder, 1998, p.22) p.ix), is that agedifferentiated social phenomena are distinct from biologically-influenced life-cycle stages. While true to some degree, we cannot ignore the role that biology plays; to develop a broad understanding of life course across populations we need to understand how biologically-influenced developmental patterns interact with cultural practices to influence health behaviours and health outcomes.

\section{Life course and developmental stages are social not just individual events.}

In many distinct societies, the biological transitions of all people, youth in particular, are carefully monitored by kin and when an individual shows physically that he/she has entered into a new developmental stage 
and shows emotional and intellectual readiness to learn and adapt to that new stage, cultural processes are set in place to move that individual, and those associated with him or her, along the developmental trajectory.

\section{Culture and traditions}

The processes set into place to move an individual and his/her associates through the developmental phases are cultural ones; more specifically, for most of human history the processes have been traditional. Culture is learned, not innate behaviour, and that it is shared, not idiosyncratic (Kroeber and Kluckhohn, 1952, p.27). Whatever else culture may be (e.g., cognitive processes) it involves behaviour acquired from another individual and potentially transmittable to a third ((Palmer, 1997; Coe 2003). Traditions, on the other hand, refer to culture transmitted from one generation to the next. Traditions are, as Osaghae (2010) points out, "the legacy of the past" (p. 204). When kinship systems are strong, accepting and practicing traditions communicates respect for ancestors and the elders who teach and encourage these traditions, creating the foundation for strong social relationships that make it possible to learn important life skills from trusted individuals (Coe \& Palmer, 2008; Coe \& Palmer, 2009). The shared inheritance of traditions is often what produces the sets of individuals who share what seem to be cultural practices.

\section{Culture and Rituals}

The term "ritual" has been defined as an action or set or actions that is standardized in some way (Goody, 1977), that involves repetitive actions. Rituals, thus, would include not only good manners, but also cooperative performances. Rappaport defines traditional rituals as "the performance of more or less invariant sequences of formal acts and utterances not encoded by the performers" (1979:175), meaning that the formal acts and utterances did not originate with the performers, but come from the past, learned/memorized (or read) from the teachings of ancestors (Kaeppler, 1967). Rituals, to some extent, imply traditions.

Rituals known as rites of passage appear to have been designed to move the individual along a developmental trajectory, requiring that he/she begin to act socially in a new role, while also requiring that others acknowledge the transition and respond by treating the person differently. Rituals, as their performance both requires and promotes cooperation (e.g., through stories that tell participants cooperate with the transitioned individual by treating him/her differently) they also have been found to stabilize individuals and families during times of transition (Fiese et al., 2002) by guiding social interactions and activities of daily living in a way that promotes cooperation (Coe, 2003). Interventions that build on these traditions and deep structure values are likely to be more successful as they build not only on what is familiar but biologically influenced response patterns as well (Resnicow, Soler, Braithwaite, Ahluwalia, \& Butler, 2000). While all lifestyle interventions, following from the definition of ritual provided above, are, to some extent, rituals, they can be more successful if they address life course transitions and individual and family developmental trajectories that recognize 1) unique aspects of culture and 2) the social context within which families interact. Family developmental trajectories as used here refers to the fact that each family member is moving through specified biological transitions at the end of which he/she is now accepted as belonging to a new stage. This new model, illustrated here (Figure 1), incorporates not only a life course perspective, the identification of individual developmental milestones, and family rituals. It is critical to note that the age of completion of specific developmental stages is not irrelevant. Childbirth at a very young age 'foreshortens' a generation, and just as grandparents in their 30's may not be ready to be grandparents, youth may not be ready for the duties of parenting (p. 23). Further, if children wait too long to begin a family, their children might never know their grandparents who often lead family rituals and have an important influence on child development (Hawkes, 2005; Hawkes, 2006). 


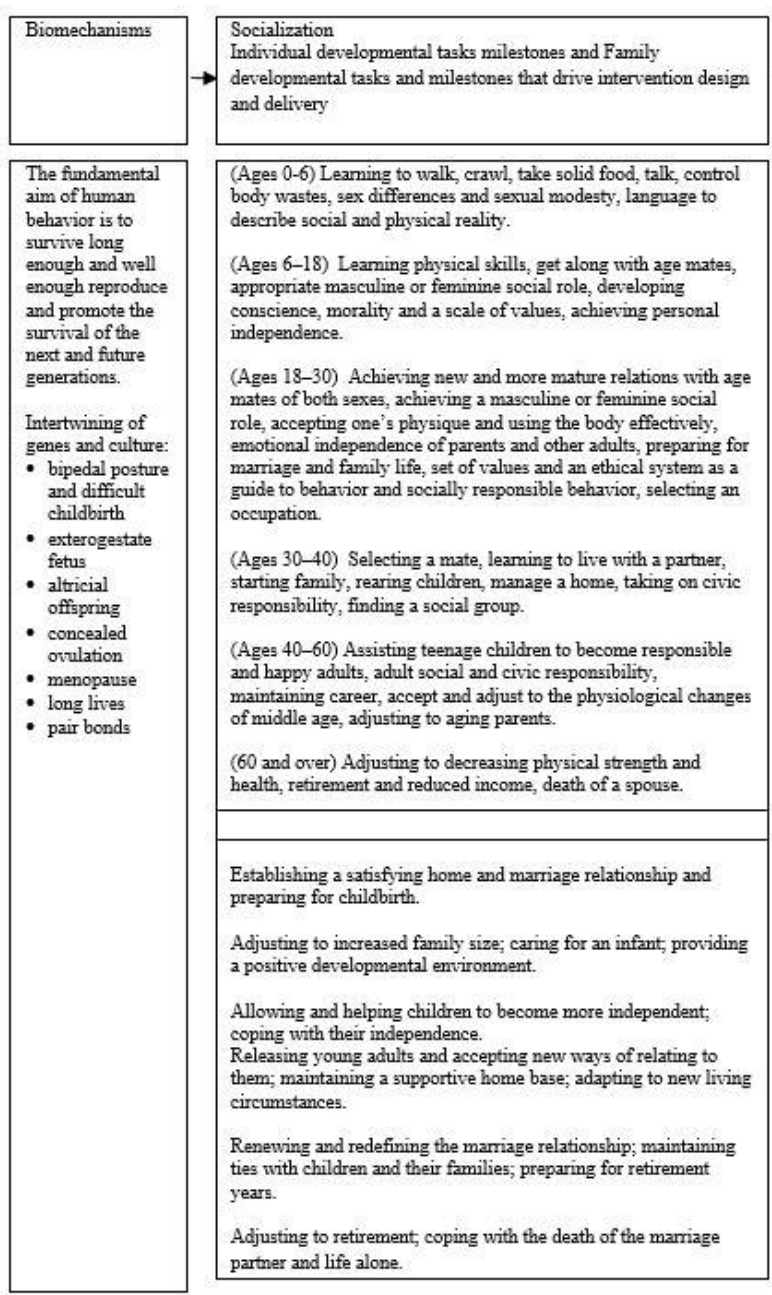

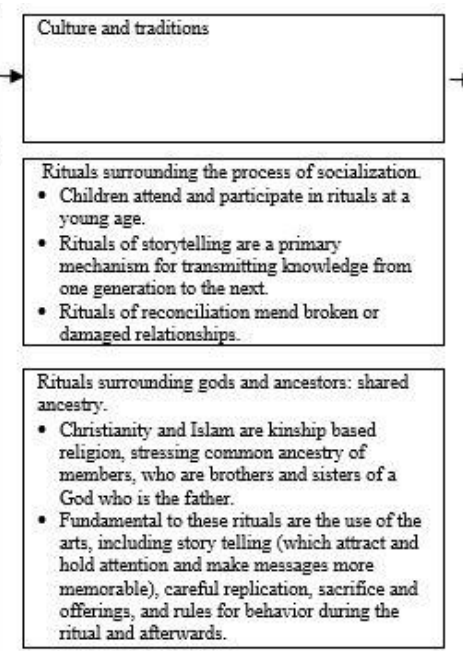

Rituals associated with developmental changes:

Many rituals are associated with rites of passage, with puberty rituals being one in which adult roles are taught. Coincide with important roles development mastery and expectations. - Rituals surrounding birth, death, marriage

Strict sexual division of labor in the performance of many ancestor rituals; both males and females have specific and complementary roles.

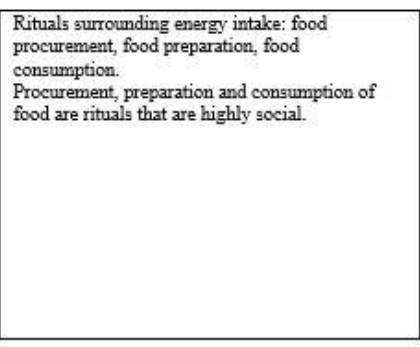

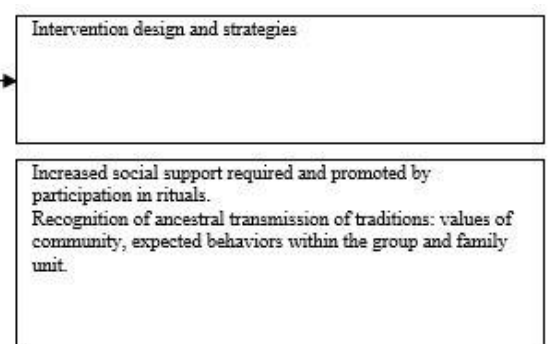

In an important sense, interventions are a form of ritual. More emphasis should be placed on ensuring they contain the traditional characteristics of rituals, which requires that they are highly social. Develop adult rituals and ensure that children participate and have a role as leaner. Emphasis importance of learning social mores. Social mores are tied to health behaviors as individuals are taught to behave in ways that benefit their family as a whole.

\section{Emotional support addresging resolution of traditional and contemporary gender roles (Marianismo/Machismo) Rituals surrounding coming of age. \\ Role modeling gender roles in health behaviors: exercise. \\ Traditional rituals mark all rites of passage, acknowledging importance of each individual and his or her unique life and developmental cycle.}

Children are provided with a road map for how to behave socially.

Reconcile gender roles in physical activity and food preparation activities

Role modeling, vicarious and replicated behaviors in shopping, cooking, presenting meals.

Figure 1: Culture and development (Duvall \& Miller, 1985; Erikson, 1950; Erikson, 1968, and Havighurst ,1972)

Figure 1 explicates our model. We first (left column) describe the origins of rituals and how they intersect with human development and survival. We next discuss human development stages (discussed below), their relationship(s) to culture and traditions, and integrate suggestions for intervention strategies.

\section{Family and Individual Development}

Decades of research by psychologists and sociologists underpin the constructs of developmental tasks. Duvall (Duvall \& Miller, 1985), Erickson (Erikson, 1950; Erikson, 1968), and Havighurst (1972) propose that there are life stages each associated with tasks that need to be mastered as people mature. While our proposed model, thus, is based upon decades of research on development task mastery this results of those studies have seldom been used to promote health despite the fact that they hold great promise for modifying health behaviours within families and across the lifespan.

\section{Age Grade}

Many societies, as does ours, classify individuals by age. The resulting age grade is associated with expectations that the person moving up into an older age grade will master the tasks associated with that grade. Entry into a new age grade is socially acknowledged and marked by rituals and new expectations. As one advances through age grades, he/she becomes progressively more senior and recognized as an authority. While classes or groupings are made up of individuals of similar age, they are guided by someone of a senior age grade. 


\section{Sex and Gender}

Among traditional people there is often a strict sexual division of labor that is, to some extent, influenced by biological factors, such as the role played in and the resources and skills needed for successful reproduction. A significant amount of family development research shows that in traditional societies, beginning early in life, boys and girls are given different developmental tasks, with girls being encouraged to learn mothering or caretaking responsibilities (Chodorow, 1978). Within a family, as the responsibility of preparing children for life and moving them through early developmental changes largely falls on a female's shoulders she has been prepared for the responsibilities she will assume, just as males are being prepared for those they will shoulder (Coe, 2003).

\section{Shared values}

Research supports that family based interventions (Biglan, Ary, \& Wagenaar, 2000; Kazdin, 1995; Patterson, Reid, \& Dishion, 1992), built on values shared in the family, are particularly effective in reducing risky behaviours thereby increasing family cohesion, and improving general health (Tobler \& Kumpfer, 2000; Tobler \& Stratton, 1997). Traditional Latino families have shared values that stress that families are important and that parents, elders, and traditions must be honored. Healthy lifestyle adaptations for risk reduction may be more readily obtained through interventions that include family values and traditions to encourage behaviour change. While these values play a role in holding families together and in teaching and learning they often are weakened by the process of acculturation.

\section{Developmental task achievements are influenced by rituals.}

The performance of rituals within families may be categorized as family celebrations, family traditions and patterned family interactions (Wolin \& Bennett, 1984). In performing rituals, family members interact, cooperate, and communicate -- behaviours that can be leveraged for intervention delivery. For example, holiday celebrations that include food preparation and procurement, and rites of passage that are culture-centric, may be deployed to apply evidenced based interventions, building family unity and engaging family members to move along the way to developmental milestones.

According to recent thinking in biology, the fundamental aim of behaviour is to survive long enough and well enough to reproduce and promote the survival of the next and future generations. Crucial to the success of this aim is rearing an offspring who has the skills to survive and thrive and continue to do so long after the death of his/her parents. Given the altriciality of human offspring, and the large human brain, the maturation and socialization process is prolonged and marked by rituals. Rituals that celebrate stages in the life course are an integral part of the strategy for preparing offspring and, indeed, moving all individuals through their life stages successfully. Rituals appear to be designed to help with transitions in both biological and cultural terms, such as from childhood to puberty, from puberty to marriage, or from middle age to old age. These defined transitions promote and require familial cooperation, thus reaffirming important social ties to outline and teach the skills needed for the new stage. (See figure 1) Despite their importance, social relationships within families are fragile, and can be damage permanently by conflict. Rituals play a role in promoting as well as repairing social relationships (Coe, Palmer, \& ElShabazz, 2013).

Rituals serve as leverage points for the interventions that we design to promote health, and include rites of passage that are associated with developmental task mastery within the family. The use of rituals in promoting health and healthy behaviours is not new. Bossard and Boll's (1950) seminal work on family rituals describe those rituals as repetitious transmissions of the family's values, attitudes and goals. Fiese et al (2002) and distinguish family routines ("what needs to be done") from family rituals ("this is who we are"). Both contribute but in distinct ways to family identity and cohesion, both of which may impact a family's engagement in health promoting behaviours. 


\section{Overarching Characteristics of Rituals}

\section{Rules governing time and place}

Rituals are performed on a patterned and predictable basis; they are, Rappaport (1999) points out, "regularly repeated at times established by clock, calendar, biological rhythm, ontology, physical condition, or defined social circumstance." Even rituals that seem spontaneous, done in response to a possible catastrophic situation, are predictable, in the sense that people know the rituals that must be performed and how to perform them. When conducting an intervention, we select a specific area that seems conducive to learning and we perform certain rituals to teach certain behaviours.

\section{Rules encourage precise replication}

The performance of a traditional ritual typically must follow "more or less punctiliously, orders established" (Rappaport, 1992) which involves following strict, often repetitive, patterns (Fogelin, 2007) that are done with formality, seriousness and intensity (Rook, 1985). Repeated rituals each step of which is predictable are comfortable practices.

\section{Rules for the audience}

It is of interest, as our intervention rituals are aimed to changing behaviour, that participants, after attending a traditional ritual, are made to understand that they are now expected to behave in the ways described portrayed, praised and rewarded in the rituals; if they fail, they face certain social consequences. This means that once an adolescent has completed his or her rites of passage, he/she is expected to act as an adult and those who know of or attended the ritual are to treat him as such.

\section{Rituals and Interventions}

\begin{tabular}{|c|c|c|}
\hline Rules for Rituals & Rites of Passage & Food procurement, Preparation, Presentation \\
\hline $\begin{array}{l}\text { Repetition: repetitious transmigsions of the family's } \\
\text { values, attitudes and goals; predictable, in the sense that } \\
\text { people know the rituals that must be performed and how } \\
\text { to perform them. }\end{array}$ & $\begin{array}{l}\text { Within family life, the movement of children and parents across life } \\
\text { course established developmental master: } \\
\text { Young children: support autonomy through acquisition of life skills } \\
\text { such as socially responsible behavior, tailored to gender and } \\
\text { physical abilities, parental guidance. }\end{array}$ & $\begin{array}{l}\text { Intervention design includes decisions regarding family mealtime: } \\
\text { minimum meals prepared together, balance between food elements } \\
\text { (fruits/vegetables/proteins etc.); traditional foods prepared with } \\
\text { balance, low fat. Family participation in food procurement, preparation } \\
\text { and consumption. Fruits and vegetables chosen for aesthetic and } \\
\text { nutritional properties. }\end{array}$ \\
\hline $\begin{array}{l}\text { Rules of timing and place: specific area that seems } \\
\text { conducive to learning and we perform certain rituals to } \\
\text { teach certain behaviors. }\end{array}$ & $\begin{array}{l}\text { Intervention delivery requires both dose and setting, interventions } \\
\text { should include settings where implementation integrates cultural } \\
\text { relevance, supports traditions, includes all family members. }\end{array}$ & $\begin{array}{l}\text { Mealtime includes table gathering at agreed upon times and } \\
\text { appropriate places, which allow for conversation and leisurely eating. } \\
\text { The tab le is arranged in an aesthetic fashion, as is the food on a plate. } \\
\text { Celebration decisions on food preparation by specific members, with } \\
\text { socialization of preparation tasks, clean up tasks that are shared among } \\
\text { gender and ages, often with a sexual division of labor in which males } \\
\text { do food preparation for rituals involving individuals from outside the } \\
\text { family, while females specialize in family events. }\end{array}$ \\
\hline $\begin{array}{l}\text { Precise replication: following strict, often repetitive, } \\
\text { pattems. }\end{array}$ & $\begin{array}{l}\text { Replication of specialized family PA activities: "always go to park } \\
\text { on Sundays"; " consistent investment in team sports with } \\
\text { children'adolescents, with adults as participant observers or } \\
\text { coaching"; consistent investment in walking before'after mealtime } \\
\text { weekdays, together on weekends. }\end{array}$ & $\begin{array}{l}\text { Replication of specialized family food preparation activities: "mother } \\
\text { always cooks, with child/adolescent preparation of foods" - chopping, } \\
\text { shopping, and baking. Again, the preparation of food is an aesthetic } \\
\text { event, compriged of attractive smells, colors, and even sounds (e.g., } \\
\text { repetitive chopping). }\end{array}$ \\
\hline $\begin{array}{l}\text { Audience rules: participants, after attending a traditional } \\
\text { ritual, are expected to behave in the ways described } \\
\text { portrayed, praised and rewarded in the rituals. }\end{array}$ & $\begin{array}{l}\text { "Rules" described for each family member according to } \\
\text { developmental tasks: older members pass on traditions through } \\
\text { story telling; adult members provide behavioral guidance and } \\
\text { expectations; younger members assigned behavioral goals matching } \\
\text { developmental stage. }\end{array}$ & $\begin{array}{l}\text { Socializing behaviors during food preparation: is how to "match" fruit } \\
\text { drinks with certain meals; how to prepare 'traditional' foods; where } \\
\text { and how family sharing of day and future plans occurs. }\end{array}$ \\
\hline Aesthetics & $\begin{array}{l}\text { To some degree rituals are aesthetic events. The aesthetics call } \\
\text { attention to the ritual and its purpose and help make it memorable. }\end{array}$ & $\begin{array}{l}\text { Meals involve making the food attractive on the plate and setting a } \\
\text { table in a way that makes it very attractive; stories are told that use } \\
\text { certain key elements, including a certain form (with an introduction } \\
\text { and conclusion), use of poetic language, with includes such things as } \\
\text { euphony, mnemonic devices, assonance, alliteration, repetition, rhyme, } \\
\text { metaphor, simile, harmony between sounds of neighboring words. } \\
\text { These are referred to as spell binding elements of stories. }\end{array}$ \\
\hline
\end{tabular}


In this section we treat rituals as two similar but distinct activities. First, there are rituals already being performed in traditional families. These rituals include such things as baptism, quinceañeras, birthdays, etc. We point out that these existing family rituals can provide the opportunity for health promotion and disease prevention (see, Table 1).

The other way we describe rituals is in terms of their key characteristics, as we might incorporate these characteristics into our interventions. We argue these characteristics are important to consider as ritualistic activities, based on evidence in the ethnographic record, that have been effective in promoting behaviour probably for thousands of years.

\section{Existing family rituals}

Rituals provide an opportunity for people to connect socially, strengthening and reaffirming ties, particularly as those ties at one time involved or were centered on a person who may no longer be there to guide the interactions. For example, Las posadas and las pastorelas, re-enactments of the time when Mary and Joseph were looking for a place to stay before Jesus was born, encourage good parenting behaviours, even when those behaviours involve significant self-sacrifice. Los farolitos y luminarias celebrate the Day of the Immaculate Conception by lighting candles and lanterns and point out the importance of virtue in young women. These rituals require family members to cooperate in preparing for and participating in the rituals and are used to reinforce the importance of family and encourage children to honor and learn from their parents.

\section{Rituals surrounding rites of passage}

Rites of passage signify family developmental trajectory mastery. For example, among Latinos, the quinceañera celebration is performed when a girl is 15 and marks her passage from girlhood to womanhood, for example if we want to leverage a ritual to encourage PA in Latinas, we might look at the pomp and circumstance that goes into the ritual and its performance and preparation including the dancing which can be expanded further to support dancing as a regular form of PA that should be incorporated into the girl's life.

Rituals for boys can encourage them to take responsibility for the family and its wellbeing. We refer to the resulting behaviours as machismo and marianismo, which refers to 'traditional' male-female values and subsequent role enactments. To counter a negative value, such as a female's unwillingness to engage in physical activity, one might develop rituals that encourage physical activity or exercise and describe it as an important activity for a Hispanic/Latino girl (Goldman et al., 2003; Gonzales \& Keller, 2004; Keller \& Gonzales-Cantu, 2008). Rituals aimed at countering the cultural value (Torres, Solberg, \& Carlstrom, 2002) referred to as marianismo, which involves serving the family's needs, which can influence a mother to neglect her own physical and emotional health in meeting the needs of others (Keller, Coe, \& Moore, 2014) can be developed to show mothers exercising while walking children to school or to the market to shop for food.

There is some evidence that as Latino families migrate to the U.S., food preparation and family eating patterns change and opportunities for PA are truncated (Guarnaccia, Vivar, Bellows, \& Alcaraz, 2012; Himmelgreen, 2007; Lindberg \& Stevens, 2011). Ritualizing activities, such as walking before or after dinner may initiate family based patterns that canstimulate interactions that define family values and move the integration of PA in families from "this is what we do" to "this is who we are" (Wolin \& Bennett, 1984).

\section{Incorporating the Key Characteristics of Rituals into Interventions}

Rituals often include art and storytelling along with performance, which, we argue, make any messages associated with the rituals more memorable. Parents in traditional societies are opportunistic storytellers who use stories to teach children the skills they now need to have, given their advancing maturity. Each developmental stage carries with it new behavioural expectations and many of these expectations are taught in stories that vividly describe social and other skills and point out the consequences associated with carefully following the 
"instructions" in the story or ignoring them. Around the world, stories teach children to be careful and responsible. Little Red Riding Hood, as one example, warns girls to be cautious when walking alone, just as the story of La Llarona warns girls to make careful choices.

\section{Rituals surrounding food and food procurement and preparation: a specific health behaviour example}

The procurement, preparation and consumption of food are rituals that are aesthetic, involving colors, smells, and sounds that are appealing.

Social gatherings among traditional people seldom fail to include food. The collective procurement of food, as one example, involves selecting the most aesthetically pleasing fruits, vegetables and meats. It, like cooking and ritually consuming foods, is not only a social event, but it is a highly aesthetic experience. When the environment in which food consumed is also aesthetic, showing evidence that great efforts were made to make the table and surrounding areas attractive, the eating process is often turned into something resembling a sacred ritual, one that often involves a prayer said at the beginning of a meal. Consumption is slowed, as conversation is encouraged, and food is more likely to be savored and to give a feeling of fullness and satisfaction. There is evidence that obesity epidemic is not only related to the consumption of high calorie fast foods, but the loss of important food rituals which slow down eating and turn eating into a highly social event (de Graaf \& Kok, 2010).

We incorporate not only serving food, but engaging participants in its procurement and preparation. For the most part, mothers, and perhaps grandmothers are primarily responsible for shopping for foodstuffs. They may engage young children in selecting wholesome foods for meal preparation. Engaging children early on in their developmental trajectory in food selection and meal planning may, in turn, may result in consuming a more nutritious diet. Mothers are most aware when both boy and girl children are ready to use cutlery and assist with vegetable and meat preparation, as well as learning about which fruits are in season and which are best paired with what main course selections. This would allow time for social interactions, for social relations between caregivers and children, and serve to guide children along the paths to independence, as well as identify components of selfsufficiency. We propose that rituals surrounding food can serve as an example of culturally relevant and developmentally staged delivery strategies that can engage families in promoting healthy nutrition behaviours.

In Table 1 (above), we highlight rituals that can be leveraged to promote physical activity and healthy eating to flesh out intervention delivery strategies and suggest delivery strategies salient to culture and family development that elucidate the model. Integrating rituals as leverage points will likely enhance the impact and sustainability of intervention effects as the family and each member transitions through their developmental stages.

\section{References}

Biglan, A., Ary, D., \& Wagenaar, C. A. (2000). The value of interrupted time-series experiments for community intervention research. Prevention Science, 1(1), 1389.

Bossard, J. H. S., \& Boll, E. S. (1950). Ritual in family living. Philadelphia: University of Pennsylvania Press.

Castro, F. G., Barrera, M.Jr, \& Martinez, C. R.Jr. (2004). The cultural adaptation of prevention interventions: Resolving tensions between fidelity and fit. Prevention Science: The Official Journal of the Society for Prevention Research, 5(1), 41-45.

Chodorow, N. J. (1978). Reproduction of mothering: Psychoanalysis and the sociology of gender. Berkeley, CA: University of California Press.

Coe, K. (2003). The ancestress hypothesis: Visual art as adaptation. New Brunswick, NJ: Rutgers University Press.

Coe, K., Palmer, C. T., \& ElShabazz, K. (2013). The resolution of conflict: Traditional African ancestors, kinship, and rituals of reconciliation. African Conflict \& Peacebuilding Review, 3(2), 110-128. doi: 10.1353/acp.2013.0019 
Coe, K., \& Palmer, C. (2008). The words of our ancestors: Kinship, tradition, and moral codes. World Cultures, 16(1), Article 1.

Coe, K., \& Palmer, C. T. (2009). How elders guided the evolution of the modern human brain, social behaviour, and culture. American Indian Culture and Research Journal, 33(3), 5-21.

de Graaf, C., \& Kok, F. J. (2010). Slow food, fast food and the control of food intake. Nature Reviews Endocrinology, 6(5), 290-293. doi:10.1038/nrendo.2010.41 [doi]

Duvall, E. R. M., \& Miller, B. C. (1985). Marriage and family development (6th ed.). New York: Harper \& Row.

Erikson, E. H. (1950). Childhood and society. New York: W. W. Norton \& Company.

Erikson, E. H. (1968). Identity: Youth and crisis. New York: W. W. Norton \& Company.

Fiese, B. H., Tomcho, T. J., Douglas, M., Josephs, K., Poltrock, S., \& Baker, T. (2002). A review of 50 years of research on naturally occurring family routines and rituals: Cause for celebration? Journal of Family Psychology: JFP : Journal of the Division of Family Psychology of the American Psychological Association (Division 43), 16(4), 381-390.

Fogelin, L. (2007). The archeology of religious ritual. Annual Review of Anthropology, 36, 55-71. doi:10.1146/annurev.anthro.36.081406.094425

Giele, J. Z., \& Elder, G. H. (1998). Methods of life course research: Qualitative and quantitative approaches. Thousand Oaks, Calif.: Sage Publications.

Goldman, R., Hunt, M. K., Allen, J. D., Hauser, S., Emmons, K., Maeda, M., \& Sorensen, G. (2003). The life history interview method: Applications to intervention development. Health Education \& Behaviour: The Official Publication of the Society for Public Health Education, 30(5), 564-581.

Gonzalez, F. G., \& Alarcon-Hernandez, E. (2002). Integrating cultural variables into drug abuse prevention and treatment with racial/ethnic minorities. Journal of Drug Issues, 32(3), 783-810.

Gonzales, A., \& Keller, C. (2004). Mi familia viene primero (my family comes first): Physical activity issues in older Mexican American women. Southern Online Journal of Nursing Research, 5(4), 21.

Goody, J. (1977). Against "ritual": Loosely structured thoughts on a loosely defined topic. In S. F. Moore, \& B. G. Myerhoff (Eds.), Secular ritual (pp. 25-35) Assen.

Green, L. W. (2001). From research to "best practices" in other settings and populations. American Journal of Health Behaviour, 25(3), 165.

Green, L. W., \& Glasgow, R. E. (2006). Evaluating the relevance, generalization, and applicability of research: Issues in external validation and translation methodology. Evaluation \& the Health Professions, 29(1), $126-153$.

Green, L. W., Ottoson, J. M., Garcia, C., \& Hiatt, R. A. (2009). Diffusion theory and knowledge dissemination, utilization, and integration in public health. Annual Review of Public Health, 30, 151-174.

Guarnaccia, P. J., Vivar, T., Bellows, A. C., \& Alcaraz, G. V. (2012). 'We eat meat every day': Ecology and economy of dietary change among Oaxacan migrants from Mexico to New Jersey. Ethnic and Racial Studies, 35(1), 104-119. doi:10.1080/01419870.2011.594170

Havighurst, R. J. (1972). Developmental tasks and education (3rd ed.). United Kindom: Longman Group. Hawkes, K. (2005). Human age structures, paleodemography, and the grandmother hypothesis. In E. Voland, A. Chasiotis \& W. Schiefenhovel (Eds.), Grandmotherhood: The evolutionary significance of the second half of the female life (pp. 118-140). New Brunswick: Rutgers University Press.

Hawkes, K. (2006). Life history theory and human evolution. In K. Hawkes, \& R. Paine (Eds.), The evolution of 
human life history (pp. 45-93). Santa Fe and Oxford: SAR Press.

Himmelgreen, D. D. (2007). "I don't make the soups anymore": Pre- to post-migration dietary and lifestyle changes among Latinos living in west-central Florida. Ecology of Food and Nutrition, 46(5-6), 427-444.

Israel, B. A., Schulz, A. J., Parker, E. A., \& Becker, A. B. (1998). Review of community-based research: Assessing partnership approaches to improve public health. Annual Review of Public Health, 19, 173-202.

Kaeppler, A. L. (1967). The structure of Togan dance. Manoa, HI: PhD thesis. University of Hawaii.

Kazdin, A. E. (1995). Conduct disorders in childhood and adolescence (2nd ed.). London: Sage Publications.

Keller, C., \& Gonzales-Cantu, A. (2008). Camina por salud: Walking in Mexican American women. Applied Nursing Research, 21(2), 110.

Keller, C. S., Coe, K., \& Moore, N. (2014). Addressing the demand for cultural relevance in intervention design. Health Promotion Practice, 15(5), 654-663. doi:10.1177/1524839914526204 [doi]

Kroeber, A. L., \& Kluckhohn, C. (1952). Culture: A critical review of concepts and definitions. Papers of the Peabody Museum of Archaeology \& Ethnology, 47(1), 223.

Osaghae, E. E. (2010). Applying traditional methods to modern conflict. In W. Zartman (Ed.), Traditional cures for modern conflicts: African conflict medicine (1st ed., pp. 183-200). Boulder, CO: Lynne Rienner Publishers Inc.

Palmer, C., \& Stedman, L. (1997). Human kinship as a descendant-leaving strategy: A solution to an evolutionary puzzle. Journal of Social and Evolutionary Systems, 20(1), 39-51.

Patterson, G. R., Reid, J. B., \& Dishion, T. J. (1992). Antisocial boys: A social interactional approach. Eugene, OR: Castalia.

Rappaport, R. A. (1979). The obvious aspects of ritual. Ecology, meaning, and religion (pp. 173-222). Richmond, CA: North Atlantic Books.

Rappaport, R. A. (1992). Ritual, time, and eternety. Zygon, 27(1), 5-30.

Rappaport, R. A. (1999). Ritual and religion in the making of humanity. Cambridge, UK: Cambridge University Press.

Resnicow, K., Soler, R., Braithwaite, R. L., Ahluwalia, J. S., \& Butler, J. (2000). Cultural sensitivity in substance use prevention. Journal of Community Psychology, 28(3), 271-290.

Rook, D. W. (1985). The ritual dimension of consumer behaviour. Journal of Consumer Research, 12(3), $251-264$.

Tobler, N. S., \& Kumpfer, K. L. (2000). Meta-analysis of family based strenthening programs. Report to CSAP/SAMHSA. (). Rockville, MD.:

Tobler, N. S., \& Stratton, H. H. (1997). Effectiveness of school-based drug prevention programs: A meta-analysis of the research. The Journal of Primary Prevention, 18(1), 71-128.

Wolin, S. J., \& Bennett, L. A. (1984). Family rituals. Family Process, 23(3), 401-420. doi:10.1111/j.15455300.1984.00401.x

Zartman, W. I. (2000). Introduction: African traditional conflict "Medicine" Traditional cures for modern conflicts: African conflict medicine (pp. 15-30). Boulder, Colorado: Lynee Rienner Publishers Inc. 